\title{
Symmetrical Six-Phase Induction Machines: A Solution for Multiphase Direct Control Strategies
}

\author{
Angel Gonzalez-Prieto \\ Department of Electrical \\ Engineering \\ University of Malaga \\ Malaga, Spain \\ anggonpri@gmail.com
}

\author{
Ignacio Gonzalez-Prieto \\ Department of Electrical \\ Engineering \\ University of Malaga \\ Malaga, Spain \\ ignaciogp87@gmail.com
}

\author{
Alejandro G. Yepes \\ Applied Power Electronics \\ Technology Research Group \\ Universidade de Vigo \\ Vigo, Spain \\ agyepes@uvigo.es
}

\author{
Mario J. Duran \\ Department of Electrical \\ Engineering \\ University of Malaga \\ Malaga, Spain \\ mjduran@uma.es
}

\author{
Jesus Doval-Gandoy \\ Applied Power Electronics \\ Technology Research Group \\ Universidade de Vigo \\ Vigo, Spain \\ jdoval@uvigo.es
}

\begin{abstract}
Six-phase induction machines are considered an interesting multiphase option because they can benefit from the well-known three-phase converter technology. These multiphase machines can be classified according to the spatial distribution of their windings into two main groups: asymmetrical and symmetrical six-phase machines. In the case of symmetrical sixphase machines, some sets of voltage vectors show an important advantage from the point of view of the $x-y$ current mitigation. They provide an active production in the $\alpha-\beta$ plane with a completely null injection of $\boldsymbol{x}$ - $\boldsymbol{y}$ components. This fact is a desired feature for direct control strategies, such as standard model predictive control (MPC), where a single switching state is applied during the entire sampling period. Based on these statements, this work proposes an MPC strategy for symmetrical six-phase induction machines using voltage vectors with null $x$-y voltage production in order to obtain the flux/torque generation with minimum $\boldsymbol{x}$-y currents. Simulated results have been included to validate the goodness of the developed control scheme.
\end{abstract}

Keywords-Model predictive control, symmetrical six-phase induction machine, voltage vectors.

\section{INTRODUCTION}

Electric drives play an important role in the current situation, where green energies and electric mobility show a sustained growth [1-2]. Thanks to the evolution in the field of the electric drives, these environmental-friendly sources/sinks of energy are nowadays serious competitors of energy systems based on fossil fuels. However, this scenario also brings higher requirements for next-generation electric drives, pushing international research groups to investigate and develop more competitive electric drives during last decade [2]. In this context, multiphase systems offer several advantages over conventional three-phase systems, including a better fault tolerance, a reduced power per phase and a higher number of freedom degrees [2]. These peculiarities allow increasing, for example, the reliability and efficiency of electric drives [3-5].
Unfortunately, to achieve these advantages a highperformance current control strategy is also required [1-5]. A good example is the widely implemented field-oriented control (FOC) with proportional-integer (PI) controllers and a pulse width modulation (PWM) stage which provides low current distortion with reduced computational burden [6-7]. However, model predictive control (MPC) techniques have demonstrated a better dynamic response and higher flexibility both in three and multiphase systems [8]. According to this fact and taking into account some additional features of MPC (e.g., its ease of implementation, particularly for one-step prediction horizons [8]), this current regulation technique is nowadays considered as a real alternative to the traditional current regulators in FOC for multiphase systems [9].

Concerning the situation of MPC in six-phase induction machines, a high percentage of works have been focused on the implementation of this regulation technique for asymmetrical six-phase machines [9-10]. This hot topic of the field appears in order to exploit MPC advantages and to overcome the limitations of standard MPC to produce a suitable current quality in this type of six-phase machines. Since the available active $\alpha$ $\beta$ voltage vectors also show an active production in the secondary $x-y$ subspace, MPC cannot provide the necessary flux/torque generation with a satisfactory mitigation of the $x-y$ currents when a single switching state is applied during the whole sampling period [11]. In summary, standard MPC presents a significant limitation: the total harmonic distortion becomes unacceptable when the stator parameters or the sampling frequency are low [11]. In order to avoid this disadvantage, different authors have proposed the utilization of virtual voltage vectors for direct control strategies such as MPC or direct torque control [11-15]. This solution is based on the utilization of several switching states during the sampling period to synthesize new voltage vectors with a reduced $x-y$ voltage production [11-15]. An acceptable performance has been 
obtained following this approach, but the improvements come at the expense of a higher complexity and switching frequency. It is important to highlight however that MPC is just a victim in this sense of the specific localization of the available active voltage vectors in the asymmetrical six-phase configuration.

Fortunately, the situation is completely different in symmetrical six-phase machines, where large voltage vectors in the $\alpha-\beta$ plane show a null production in the $x-y$ subspace. Taking advantage of this interesting feature, a simplified MPC strategy is developed in this manuscript. The proposed regulation technique only employs large and null voltage vectors as selectable switching states. Nevertheless, thanks to their advantageous localization, the current quality is suitable even when a single switching state is applied during the whole sampling period. Moreover, a simplified machine model and cost function can be employed since the selected voltage vectors present a null $x-y$ production. Consequently, this approach also reduces the computational cost, another claimed disadvantage of MPC strategies [10].

This work has been structured in five sections. A description of the six-phase electric drive under consideration is included in Section II. Section III presents the MPC strategy using the proposed subset of voltage vectors. Section IV validates the goodness of the proposal with simulation results, and the main conclusions are finally summarized in Section V.

\section{Generalities of SymmetricAl SiX-Phase EleCtriC DRIVES}

The multiphase electric drive topology studied in this work is depicted in Fig. 1. It is characterized by the use of a symmetrical six-phase induction machine (IM) regulated with a dual three-phase voltage source converter (VSC). The multiphase induction machine under study is formed by two sets of three-phase windings, spatially shifted 60 degrees, providing a symmetrical spatial distribution to the IM. These windings are configured with two isolated neutral points and fed by a dual two-level three-phase VSC connected to a single dc-link. This configuration of the VSC provides $2^{6}=64$ switching states. A vector $[S]=\left[S_{a 1}, S_{b 1}, S_{c 1}, S_{a 2}, S_{b 2}, S_{c 2}\right]$ can then be employed to express the switching state of each VSC leg. If the upper switch is ON and the lower switch is OFF $S_{i}=1$ whereas $S_{i}=$ 0 when the opposite situation occurs. Stator phase voltages $\left(v_{i}\right)$ can be obtained from the dc-link voltage $\left(V_{D C}\right)$ and switching states $\left(S_{i}\right)$ as follows:

$$
\left[\begin{array}{l}
v_{a 1} \\
v_{b 1} \\
v_{c 1} \\
v_{a 2} \\
v_{b 2} \\
v_{c 2}
\end{array}\right]=\frac{V_{D C}}{3} \cdot\left[\begin{array}{rrrrrr}
2 & -1 & -1 & 0 & 0 & 0 \\
-1 & 2 & -1 & 0 & 0 & 0 \\
-1 & -1 & 2 & 0 & 0 & 0 \\
0 & 0 & 0 & 2 & -1 & -1 \\
0 & 0 & 0 & -1 & 2 & -1 \\
0 & 0 & 0 & -1 & -1 & 2
\end{array}\right] \cdot\left[\begin{array}{c}
S_{a 1} \\
S_{b 1} \\
S_{c 1} \\
S_{a 2} \\
S_{b 2} \\
S_{c 2}
\end{array}\right]
$$

Although, phase variables can describe the behavior of these systems in the field of electric drives, different reference frames have also been employed for simplification purposes [2]. One of the most popular approaches is the vector space decomposition (VSD), where phase variables are transformed into a stationary reference frame with a new physical meaning of the different components. In the case of six-phase induction machines, phase variables are transformed into two orthogonal planes and two zero-sequence components when the VSD is applied. In this reference frame, the $\alpha-\beta$ plane is related to the flux/torque production, whereas the $\mathrm{x}-y$ plane only produces stator copper losses in distributed-winding machines with negligible spatial harmonics. On the other hand, zero-sequence components cannot flow if two isolated neutral points are used. The VSD can be obtained using the current-invariant Clarke transformation:

$$
\left[T_{V S D}\right]=\frac{1}{3}\left[\begin{array}{cccccc}
1 & -1 / 2 & -1 / 2 & 1 / 2 & -1 & 1 / 2 \\
0 & \sqrt{3} / 2 & -\sqrt{3} / 2 & \sqrt{3} / 2 & 0 & -\sqrt{3} / 2 \\
1 & -1 / 2 & -1 / 2 & -1 / 2 & 1 & -1 / 2 \\
0 & -\sqrt{3} / 2 & \sqrt{3} / 2 & \sqrt{3} / 2 & 0 & -\sqrt{3} / 2 \\
1 & 1 & 1 & 0 & 0 & 0 \\
0 & 0 & 0 & 1 & 1 & 1
\end{array}\right]
$$

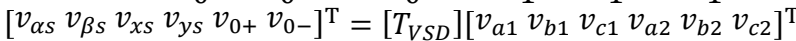

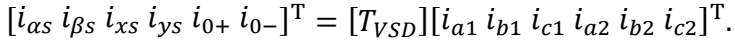

Applying (2) to the phase voltages of a symmetrical sixphase IM, it is possible to map them in $\alpha-\beta$ and $x-y$ planes (Fig. 2). These voltage vectors are identified in Fig. 2 using a decimal number corresponding to the binary number of the switching state. Depending on the $\alpha-\beta$ and $x-y$ amplitude of each voltage vector, they can be sorted into six different groups: large $\left(C_{l}\right)$, medium $\left(C_{m}\right)$, small-1 $\left(C_{s 1}\right)$, small-2 $\left(C_{s 2}\right)$, null $\alpha-\beta$ $\left(C_{n \alpha \beta}\right)$ and null voltage vectors $\left(C_{n}\right)$. The voltage contribution of these possible control actions is shown in Table I. Furthermore, the $R_{\alpha \beta}$ ratio [11] has also been included in Table I to analyze the capability of the available voltage vectors to provide a suitable performance in both planes:

$$
R_{\alpha \beta}=\sqrt{v_{\alpha s}^{2}+v_{\beta S}^{2}} / \sqrt{v_{x S}^{2}+v_{y s}^{2}} .
$$

Based on its definition, the $R_{\alpha \beta}$ parameter quantifies the relative production in both planes of each set of voltage vectors and thus, it can be employed as a quality index for the different control actions. As shown in Table I, the $R_{\alpha \beta}$ value of null $\alpha-\beta\left(C_{n \alpha \beta}\right)$ and null $\left(C_{n}\right)$ voltage vectors is zero, because both sets are characterized by a null production in the $\alpha-\beta$ plane (Fig. 2a). However, $C_{n \alpha \beta}$ voltage vectors provide an unacceptable control action to MPC due to their non-null contribution in $x-y$ plane. Focusing on small voltage vectors, the $C_{s 1}$ set shows a unity $R_{\alpha \beta}$ value, whereas, in the case of $C_{s 2}$, this parameter decreases down to 0.61 . According to these results, both groups of small voltage vectors have also been discarded as selectable switching states in this work. In the case of medium voltage vectors $\left(C_{m 1}\right)$, the $R_{\alpha \beta}$ ratio is 1.73 . Although this set shows a better value of the employed quality index, the minimization of $x-y$ components can be further enhanced by employing instead large voltage vectors $\left(C_{l}\right)$, since they reach the maximum $R_{\alpha \beta}$ value (infinite), as shown in Table I. This fact allows the obtention of a maximum flux/torque production with a null injection of $x$ $y$ components (Fig. 2c). Based on this analysis, only large $\left(C_{l}\right)$ and null $\left(C_{n}\right)$ voltage vectors are considered as available control actions in the MPC described in the next section. To the knowledge of the authors, this is the first time that the regulation of a symmetrical six-phase drive is only based on these vectors; on the contrary, vectors with $x-y$ projection are usually employed for these drives [6,16-17]. 


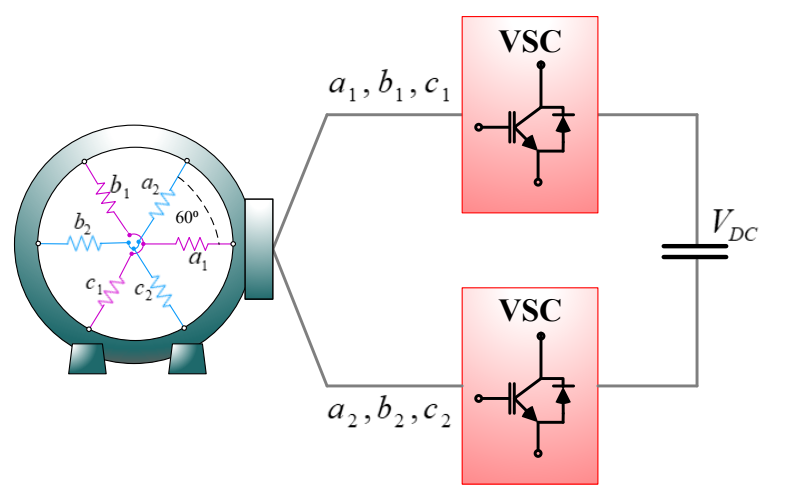

Fig. 1. Symmetrical six-phase IM fed by a dual three-phase VSC.

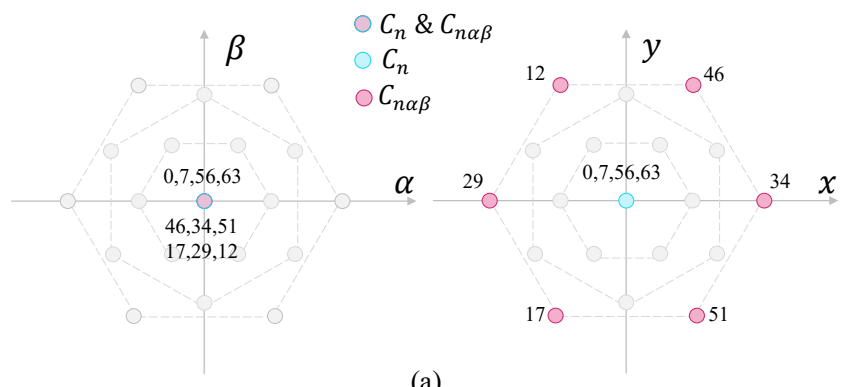

(a)

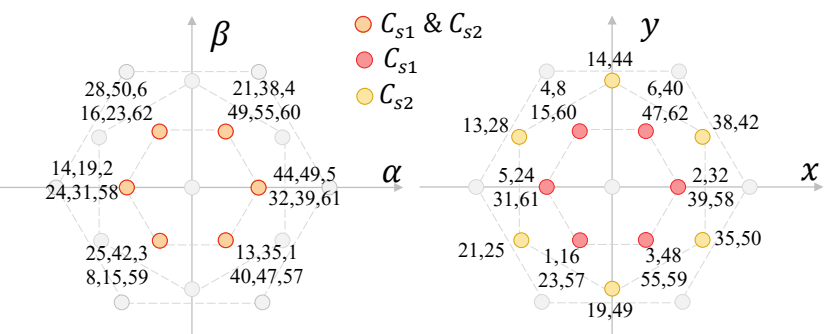

(b)

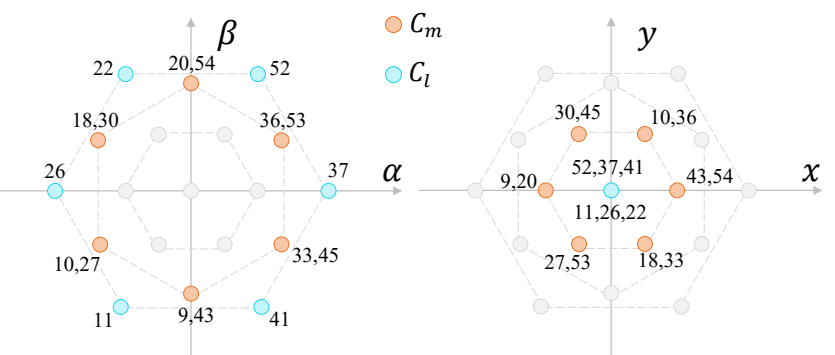

(c)

Fig. 2. Voltage vectors in $\alpha-\beta$ and $x-y$ subspaces for a symmetrical sixphase IM drive. From top to bottom: (a) $C_{n \alpha \beta} \& C_{n}$, (b) $C_{s 1} \& C_{s 2}$ and (c) $C_{m} \& C_{l}$ voltage vector sets.

TABLE I. RATIO OF PRODUCTION $v_{\alpha \beta}$ AND $v_{x y}$

\begin{tabular}{|c|c|c|c|c|c|c|}
\cline { 2 - 7 } \multicolumn{1}{c|}{} & $\boldsymbol{C}_{\boldsymbol{l}}$ & $\boldsymbol{C}_{\boldsymbol{m} \mathbf{1}}$ & $\boldsymbol{C}_{\boldsymbol{s} \mathbf{1}}$ & $\boldsymbol{C}_{\boldsymbol{s} \mathbf{2}}$ & $\boldsymbol{C}_{\boldsymbol{n} \boldsymbol{\alpha} \boldsymbol{\beta}}$ & $\boldsymbol{C}_{\boldsymbol{n}}$ \\
\hline$\left|\boldsymbol{v}_{\boldsymbol{\alpha} \boldsymbol{\beta}}\right| \cdot \mathbf{1 0 0}$ & 66.67 & 54.74 & 33.33 & 33.33 & 0 & 0 \\
\hline$\left|\boldsymbol{v}_{\boldsymbol{x y} y}\right| \cdot \mathbf{1 0 0}$ & 0 & 33.33 & 33.33 & 54.74 & 66.67 & 0 \\
\hline $\boldsymbol{R}_{\boldsymbol{\alpha} \boldsymbol{\beta}}$ & $\infty$ & 1.73 & 1 & 0.61 & 0 & 0 \\
\hline
\end{tabular}

\section{Model Predictive Control For Symmetrical SiX-} PHASE ELECTRIC DRIVES

Regardless of the MPC version, the main goal of this control technique is the regulation of the reference speed providing, at the same time, minimum stator copper losses. For this purpose, a common solution is to implement an outer speed loop with a PI controller and inner current control loops to select the optimal control action. To estimate the voltage requirements at each sampling period, the first stage is the evaluation of the available control actions in a predictive model in order to estimate the future currents $\left(\hat{l}_{\alpha \beta x y}\right)$. Later, in a second stage, reference $\left(i_{\alpha \beta x y}^{*}\right)$ and predicted $\left(\hat{\imath}_{\alpha \beta x y}\right)$ currents are compared in a predefined cost function to select the switching state which offers the minimum value of this cost function. In the case of the proposed MPC based on the utilization of large and null voltage vectors, its scheme shows some singularities due to the specific localization of the large voltage vectors in symmetrical sixphase induction machines (Fig. 2c). This set of voltage vectors has a null production of $x-y$ voltages and therefore, these components can be directly regulated in open-loop mode with the application of these switching states. Taking advantage of this fact, a simplified predictive model without secondary components can be implemented to predict the future currents:

$$
\begin{gathered}
\frac{d}{d t}\left[X_{\alpha \beta}\right]=[\bar{A}] \cdot\left[X_{\alpha \beta}\right]+[\bar{B}] \cdot\left[U_{\alpha \beta}\right] \\
{\left[Y_{\alpha \beta}\right]=[\bar{C}] \cdot\left[X_{\alpha \beta}\right],}
\end{gathered}
$$

where:

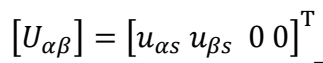

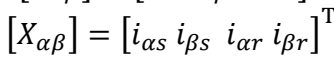

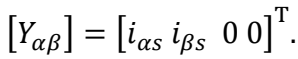

The matrices $[A],[B]$ and $[C]$ define the dynamics of a symmetrical six-phase IM and their coefficients are dependent on the machine parameters [10].

Following the same approach, a simplified cost function without $x-y$ terms is implemented in the proposed MPC version:

$$
J=\left(i_{\alpha s}^{*}-\hat{\imath}_{\alpha s}\right)^{2}+\left(i_{\beta s}^{*}-\hat{\imath}_{\beta s}\right)^{2} .
$$

To sum up, an MPC strategy with a reduced computational burden and complexity can be implemented thanks to the suitable localization of large voltage vectors in symmetrical sixphase induction machines. Fig. 3 illustrates the scheme of the proposed MPC method, where an outer PI controller guarantees the tracking of the reference speed. The iterative process considered in Fig. 3 permits the selection of the better switching state in each sampling period $\left(S^{o p t}\right)$. This control scheme has been assessed in the next section using numerical simulations.

\section{Simulation RESUlts}

This section includes simulation results to illustrate the performance of the proposed MPC for a symmetrical six-phase induction machine. The aforementioned control scheme is implemented using Matlab/Simulink software. Simulation and electrical drive parameters are included in Table II. Four different tests have been carried out to study the behavior of the control strategy in different operating conditions. Test A and test $\mathrm{B}$ verify the steady-state performance at low and high speed/torque requirements, whereas test $\mathrm{C}$ explores the control response in a dynamic situation. Finally, test D evaluates the impact of speed and torque conditions on the total harmonic distortion of phase currents, the root mean square of phase currents and the switching frequency. 


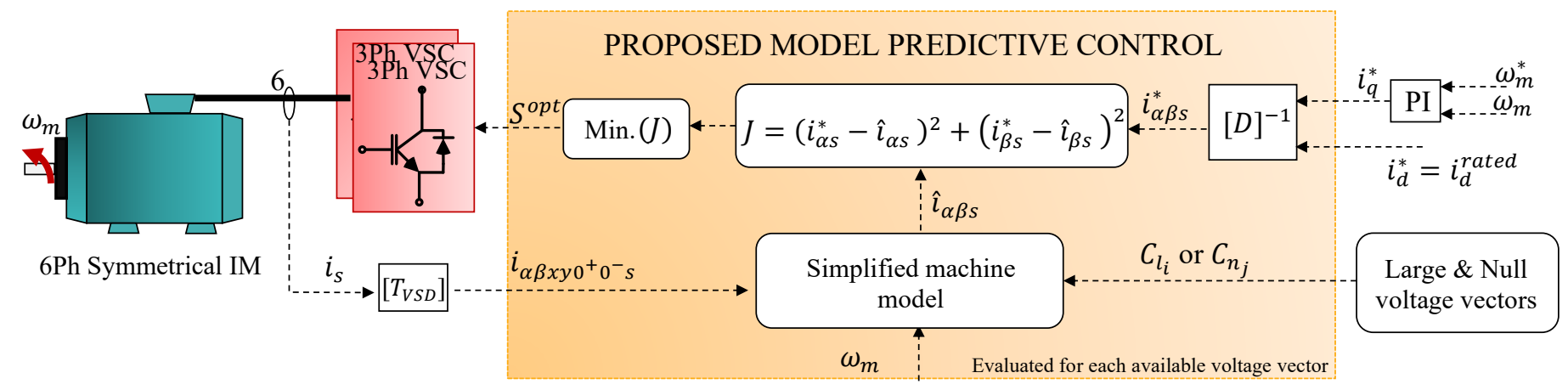

Fig. 3. Scheme of the proposed MPC where subscripts $d$ and $q$ denote direct and quadrature currents related with $\alpha-\beta$ components via Park matrix transformation $[D]$ [3] and superscripts '*' and '^’ are employed to identify reference and predicted variables, respectively. On the other hand, $i_{s}$ is a vector formed by measured phase stator currents.

\section{A. Test A. Low-Speed Condition}

In test $\mathrm{A}$, the reference speed is set at $200 \mathrm{rpm}$ and the load torque is equal to $2 \mathrm{Nm}$. The results are depicted in Fig. 4 and the main quality indices are summarized in Table III. These indices are the root main square of phase currents $\left(r m s_{p h}\right)$, the standard deviation of $x-y$ currents $\left(\sigma_{x y}\right)$, the total harmonic distortion of phase currents $\left(T H D_{p h}\right)$, the relative offset between the reference/measurement $q$ current $(\Delta q)$ and the average switching frequency $\left(f_{s w}\right)$. The speed regulation is successfully achieved (Fig. 4a) and $d-q$ currents present a satisfactory tracking of their reference values (Fig. $4 b)$. Analyzing $x-y$ currents, they show a null average value without any ripple (Fig. 4c), as it was expected on the basis of the theoretical description provided in Section II. This achievement is obtained thanks to the null production in the $x-y$ plane of the selected voltage vectors. This fact allows satisfying the flux/torque requirements with a minimum value of the $x-y$ stator copper losses, even if a single switching state is applied during the whole sampling period. As a result, phase currents show a sinusoidal waveform with a low harmonic distortion (Fig. 4d and Table III).

\section{B. Test B. High-Speed Condition}

Test B analyzes the MPC performance for a symmetrical six-phase induction machine when a high-requirement operating condition is set $(700 \mathrm{rpm}$ and $5 \mathrm{Nm}$, as shown in Fig. 5). The tracking of the reference speed and $d$ - $q$ currents is effectively done (Fig. 5a and Fig. 5b). As in test A, $x-y$ currents again present a null value regardless of the operating conditions (see Fig. 5c) thanks to the suitable behavior of large voltage vectors in the secondary subspace (Fig. 2). This fact promotes the obtention of an acceptable ripple in the phase currents (Fig. 5d) and, consequently, a reduced total harmonic distortion (see Table III).

TABLE II. SimUlation AND ELECTRIC DRIVE PARAMETERS

\begin{tabular}{|l|c|}
\hline \multicolumn{1}{|c|}{ Parameter } & Value \\
\hline Power $(\mathrm{kW})$ & 1 \\
\hline Stator resistance $(\Omega)$ & 14.195 \\
\hline Rotor resistance $(\Omega)$ & 3 \\
\hline Stator Leakage Inductance $(\mathrm{mH})$ & 4.5 \\
\hline Rotor Leakage Inductance $(\mathrm{mH})$ & 55.12 \\
\hline Mutual Inductance $(\mathrm{mH})$ & 370 \\
\hline DC-link voltage $(\mathrm{V})$ & 300 \\
\hline Simulation time $\mathrm{step}(\mu \mathrm{s})$ & 1 \\
\hline Sampling period $(\mu \mathrm{s})$ & 100 \\
\hline
\end{tabular}

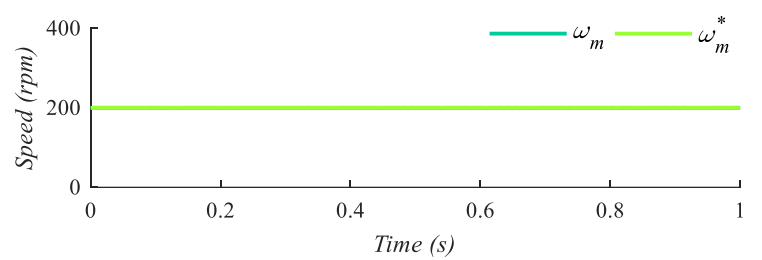

(a)

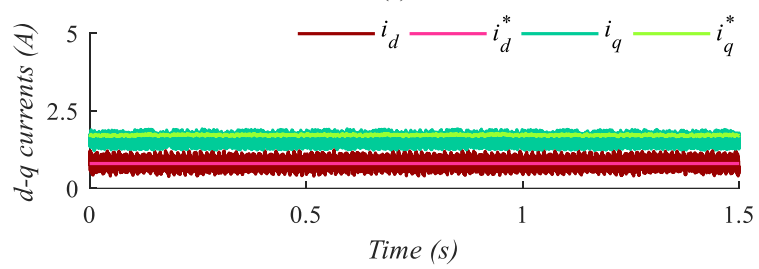

(b)

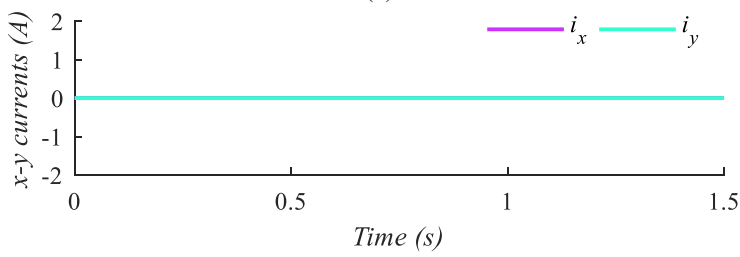

(c)

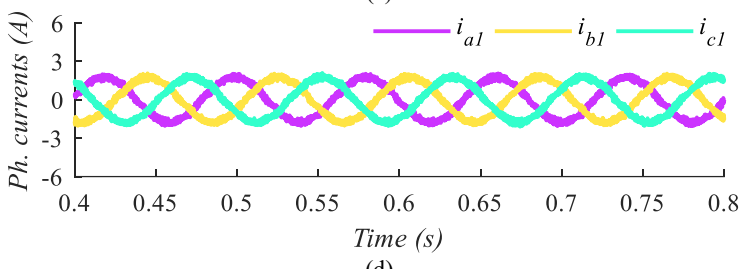

(d)

Fig. 4. Test A: Steady-state performance at low-speed and -torque condition. From top to bottom: (a) motor speed, (b) $d-q$ currents, (c) $x-y$ currents and (d) set 1 of phase currents. Test conditions: $\omega_{m}=200 \mathrm{rpm}$, $T_{\text {load }}=2 \mathrm{Nm}$.

TABLE III. TEST A AND B: QUALITY INDICES

\begin{tabular}{|c|c|c|}
\hline Parameters & Test A & Test B \\
\hline$r m s_{p h}(\mathrm{~A})$ & 1.25 & 2.78 \\
\hline$\sigma_{x y}(\mathrm{~A})$ & 0 & 0 \\
\hline$T H D_{p h}(\%)$ & 8.74 & 3.49 \\
\hline$f_{s w}(\mathrm{~Hz})$ & 4060 & 2200 \\
\hline$\Delta q(\%)$ & 8.37 & 4.55 \\
\hline
\end{tabular}




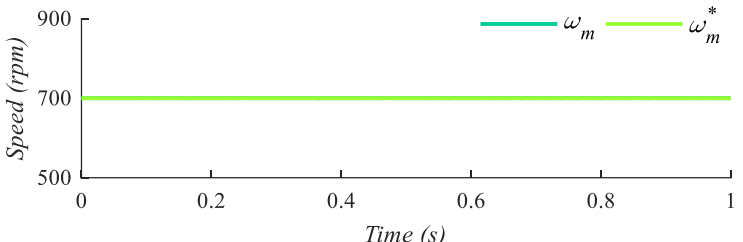

(a)

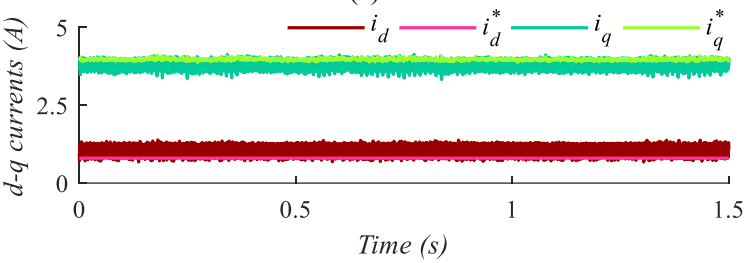

(b)

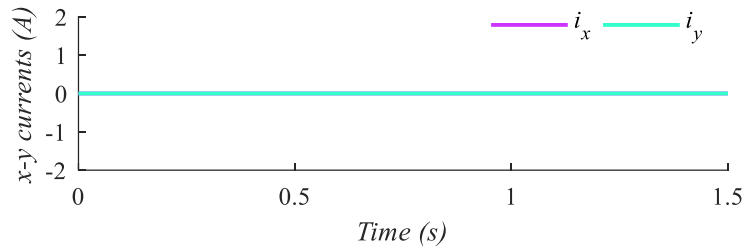

(c)

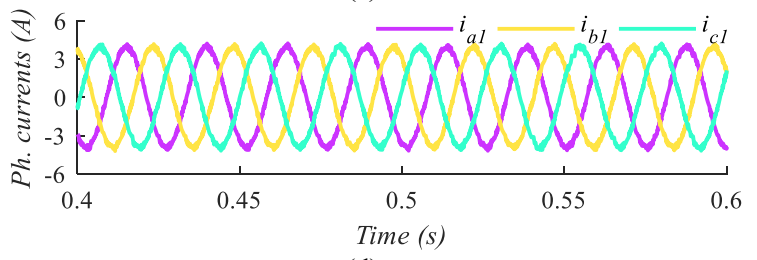

(d)

Fig. 5. Test B: Steady-state performance at high-speed and -torque condition. From top to bottom: (a) motor speed, (b) $d$-q currents, (c) $x-y$ currents and (d) set 1 of phase currents. Test conditions: $\omega_{m}=700 \mathrm{rpm}, T_{\text {load }}=5 \mathrm{Nm}$.

\section{Test C. Dynamic-State Performance}

Test $\mathrm{C}$ evaluates the capability of the proposed MPC to provide a suitable dynamic response. For this purpose, the speed reference varies from $200 \mathrm{rpm}$ to $700 \mathrm{rpm}$ following a ramp profile (Fig. 6a). On the other hand, load torque is fixed at $3 \mathrm{Nm}$ during the whole test. From the point of view of the speed regulation, the implemented control scheme achieves a satisfactory regulation even when a reduced set of voltage vectors are included as selectable switching state, as proposed. In order to track the reference speed, the $q$ reference current varies when the dynamic situation appears, as shown in Fig. 6b. As expected, $x-y$ currents also maintain their null value in the dynamic situation set in this test (Fig. 6c).

\section{Test D. Impact of Speed/Torque on Quality Indices}

Finally, three operating indices have been mapped in Fig. 7 to validate the goodness of the proposed MPC in a wide operating range. The objective of Fig. 7 is to illustrate the impact of the speed and load torque on the total harmonic distortion, the root mean square, and the average switching frequency when the proposed MPC based on large voltage vectors is implemented for a symmetrical six-phase machine.

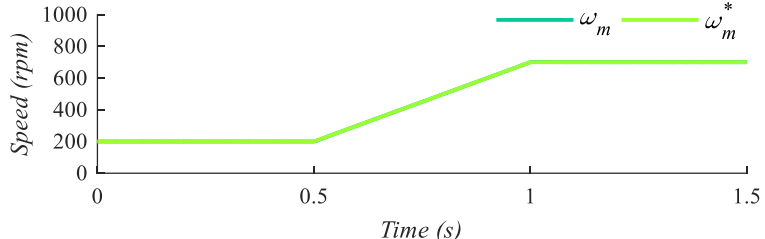

(a)

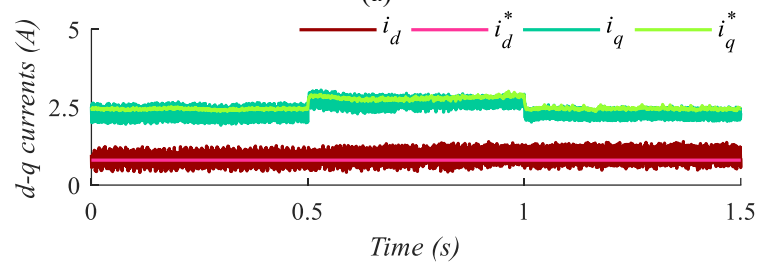

(b)

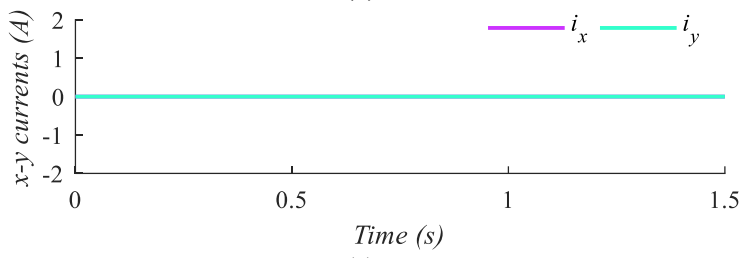

(c)

Fig. 6. Test C: Dynamic-state performance. From top to bottom: (a) motor speed, (b) $d-q$ currents and (c) $x-y$ currents. Test conditions: $\omega_{m}=200 \rightarrow 700 \mathrm{rpm}, T_{\text {load }}=3 \mathrm{Nm}$.

Focusing on the total harmonic distortion (Fig. 7a), the value of this parameter decreases when the speed/torque conditions are higher. This is because the amplitude of fundamental frequency current increases according to the operating situation, whereas $x-y$ currents are maintained close to a null value regardless of the operating conditions (Fig. 7b). This higher current requirement is obtained without any injection of $x-y$ currents. In agreement to the foregoing, a minimum value of $T H D_{p h}(3.54 \%)$ is obtained when the speed and the load torque reach their maximum values. Regarding the average switching frequency, it shows lower values for higher values of speed and torque. This result can be explained using the following reasoning: transition between two large adjacent voltage vectors implies a smaller number of switch changes compared to the transition from large to null voltage vectors. In high operating conditions, large voltage vectors are selected in a higher percentage and, consequently, the switching frequency decreases (Fig. 7c). As a conclusion of Fig. 7, an appropriate value of the quality indices is obtained in spite of the low average switching frequency.

\section{CONCLUSION}

The limitations of standard model predictive control in asymmetrical six-phase induction machines are mainly caused by the unfortunate nature of the available control actions. In MPC the control actions are the selectable voltage vectors, and in the case of an asymmetrical six-phase machine, all active voltage vectors in $\alpha$ - $\beta$ plane produce, inevitably, the injection of $x-y$ currents. For this reason, standard MPC cannot provide active flux/torque production with a low value of the secondary components if a single switching state is applied during the whole sampling period. 
Fortunately, this situation disappears in symmetrical sixphase machines thanks to the suitable localization of large voltage vectors. This set of voltage vectors shows a high production in the $\alpha-\beta$ subspace with a null contribution in the $x-y$ plane. This desirable feature permits proposing a simplified model predictive control where a single switching state per sampling period is applied. Despite of this fact, the total harmonic distortion of phase voltages is low. It can be hence concluded that symmetrical machines with their inherent multiphase advantages become an ideal choice for the implementation of direct controllers, allowing the use of a simplified control scheme that provides higher current quality and low copper losses. Potential aspects for further work include experimental validation and comparison with other alternatives in multiple operating conditions.

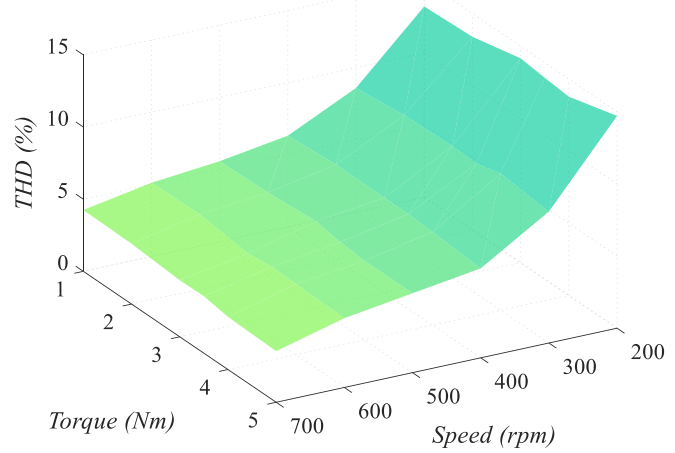

(a)

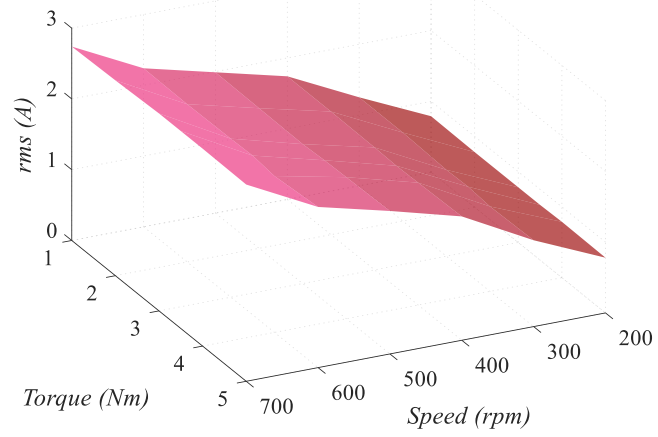

(b)

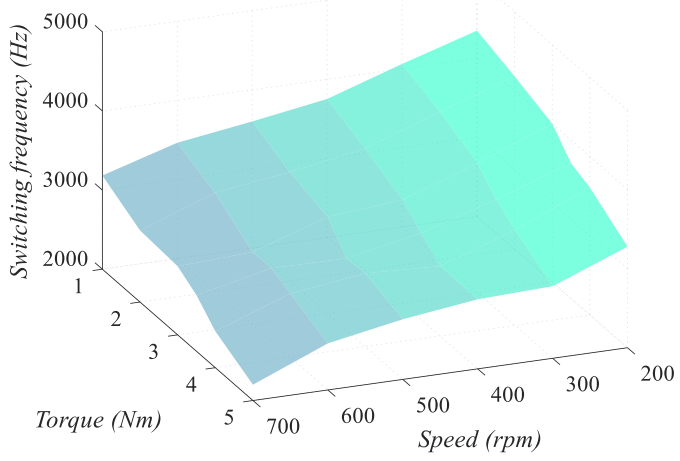

(c)

Fig. 7. Surface speed-torque impact on: (a) total harmonic distortion of phase currents, (b) root mean square of phase currents and (c) switching frequency.

\section{ACKNOWLEDGMENT}

This work was supported in part by the Ministry of Science, Innovation and Universities under the Ramon y Cajal grant RYC2018-024407-I and under project (RTI2018096151-B-I00), in part by the Spanish Ministry of Science and Innovation and by the European Commission, European Regional Development Fund (ERDF) under project PID2019-105612RB-I00.

\section{REFERENCES}

[1] G. K. Singh, "Multi-phase induction machine drive research-A survey," Electr. Power Syst. Res., vol. 61, no. 2, pp. 139-147, 2002.

[2] E. Levi, R. Bojoi, F. Profumo, H. A. Toliyat and S. Williamson, "Multiphase induction motor drives - A technology status review," IET Electr. Power Appl., vol. 1, no. 4, pp. 489-516, Jul. 2007.

[3] I. González, M. J. Duran, P. Garcia and M. Bermudez, "Field oriented control of multiphase drives with passive fault-tolerance" IEEE Trans. Ind. Electron., vol. 67, no. 9, pp. 7228-7238, Sep. 2020.

[4] A. G. Yepes, J. Doval-Gandoy and H. A. Toliyat, "Strategy with smooth transitions and improved torque-speed region and stator copper loss for two-level asymmetrical six-phase induction motor drives under switch faults," IEEE Trans. Power Electron., vol. 36, no. 2, pp. 19541969, Feb. 2021.

[5] A. Taheri, A. Rahmati and S. Kaboli, "Efficiency improvement in DTC of six-phase induction machine by adaptive gradient descent of flux," IEEE Trans. Power Electron., vol. 27, no. 3, pp. 1552-1562, Mar. 2012.

[6] D. Glose and R. Kennel, "Continuous space vector modulation for symmetrical six-phase drives," IEEE Trans. Power Electron., vol. 31, no. 5, pp. 3837-3848, May 2016.

[7] R. Bojoi, M. Lazzari, F. Profumo and A. Tenconi "Digital fieldoriented control for dual three-phase induction motor drives," IEEE Trans. Ind. Appl., vol. 39, no. 3, pp. 752-760, May-Jun. 2003.

[8] H. A. Young, M. A. Perez, J. Rodriguez and H. Abu-Rub, "Assessing finite-control-set model predictive control: A comparison with a linear current controller in two-level voltage source inverters," IEEE Ind. Electron. Mag., vol. 8, no. 1, pp. 44-52, Mar. 2014.

[9] P. Gonçalves, S. Cruz and A. Mendes, "Finite control set model predictive control of six-phase asymmetrical machines-An overview," Energies, vol. 12, no. 4693, pp. 1-42, Dec. 2019.

[10] F. Barrero, M. R. Arahal, R. Gregor, S. Toral, and M. J. Duran, "A proof of concept study of predictive current control for VSI-driven asymmetrical dual three-phase AC machines," IEEE Trans. Ind. Electron., vol. 56, no. 6, pp. 1937-1954, Jun. 2009

[11] P. Garcia, I. Zoric, I. Gonzalez, M Duran and E. Levi, "Direct torque and predictive control strategies in nine-phase electric drives using virtual voltage vectors," IEEE Trans. Power Electron., vol. 34, no. 12, Dec. 2019.

[12] J. K. Pandit, M. V. Aware, R. Nemade and Y. Tatte, "Simplified implementation of synthetic vectors for DTC of asymmetric six-phase induction motor drives," IEEE Trans. Ind. Appl., vol. 54, no. 3, pp. 2306-2318, May-Jun. 2018.

[13] Y. Luo and C. Liu, "Multi-vectors based model predictive torque control for a six-phase PMSM motor with fixed switching frequency," IEEE Trans. Energy Convers., vol. 34, no. 3, pp. 1369-1379, Sep. 2019

[14] P. F. C. Gonçalves, S. M. A. Cruz, and A. M. S. Mendes, "fixed and variable amplitude virtual vectors for model predictive control of sixphase PMSMs with single neutral configuration," IEEE International Conference on Industrial Technology, Melbourne, Australia, Jul. 2019.

[15] P. F. C. Gonçalves, S. M. A. Cruz and A. Mendes, "Predictive current control of six-phase permanent magnet synchronous machines with modulated virtual vectors," $45^{\text {tg }}$ Industrial Electronics Conference (IEEE), Lisbon, Portugal, Oct. 2019.

[16] D. Dujic, A, Iqbal and E. Levi, "A space vector PWM technique for symmetrical six-phase voltage source inverters", EPE J., vol. 17, no. 1, pp. 24-32, Sep. 2015.

[17] B. M. Shihab, M. Tousizadeh, and H.S. Che, "Continous and discontinous PWM methods for symmetrical six-phase induction motor with single isolated neutral", Arab. J. Sci. Eng., vol. 45, pp. 1885-1895, Dec. 2019. 